ISAHP 2005, Honolulu, Hawaii, July 8-10, 2005

\title{
Evaluation of the economic policy about the Aichi Exposition 2005 from the viewpoint of corporate strategy
}

\author{
Kazuyoshi Yonemoto \\ Management Planning Division, Kawamura Electoric.Inc. \\ 3-86 Akatsuki-cho,Seto, Aichi 489-0071-Japan \\ ka-yonemoto@kawamura.co.jp \\ Toshimasa Ozaki \\ Faculty of Commerce, Nagoya Gakuin University \\ 1350 Kamishinano-chyo,Seto Aichi 480-1298-Japan \\ ozaki@ngu.ac.jp
}

Keywords: Multiple criteria, corporate strategy, Exposition2005, Economic policy

Summary: It is difficult to give a rational basis the "Aichi Exposition 2005". As one of the methods which aim at people's agreement formation to the strategic event, a multiple-purpose evaluation method seems to be possible to evaluate from the viewpoint of corporate strategy. This paper describes the rationality of the venues of the "Aichi Exposition 2005" by using the AHP from the theory of corporate strategy. The criteria were extracted from the viewpoint of the corporate strategy, alternative was each heartland region of eight an economic block as for the Japanese whole country, and the priority was evaluated by the absolute measurements method. Moreover the AHP was attempted to extend to the ANP, then the results showed that eigenvalue method is superior to Super Matrix method in the diagonal matrix to all one. At the end of the paper it was pointed out that Aichi led to the best for the venue and the economic policy needed to change.

\section{Evaluation viewpoint to Exposition}

\subsection{Multipurpose evaluation and corporate strategy conception}

The difference between the country, the local government, and the enterprise is whether to take the concept of strategy to the decision making. To the regret, it is a current state in the country and the municipality that the concept of strategy is extremely scarce. Then, the candidate site evaluation for the Expo has to be evaluated from the aspect of the corporate strategy by a strategic positioning to secure competing domination which is one of the five forces shown by M.E.Porter ${ }^{(1)}$.

Here, a large area region was considered to be one enterprise, and each enterprise was evaluated by a business area, an economy, a reformation, and financial power. These candidate sites were made eight regions, Hokkaido, Tohoku, Kanto, Chubu, Kansai, Chugoku, Shikoku, and Kyushu that the Ministry of Economy by Trade and Industry divided.

\subsection{Evaluation by priority level}


The past to the Expo has been based on the technique of econometrics ${ }^{(2)}$, which was the money scale. The region where the effect of drawing customers was high was given to priority, and the doubt with "Why did the venue be the region?" couldnot be answered in an economic evaluation alone. We

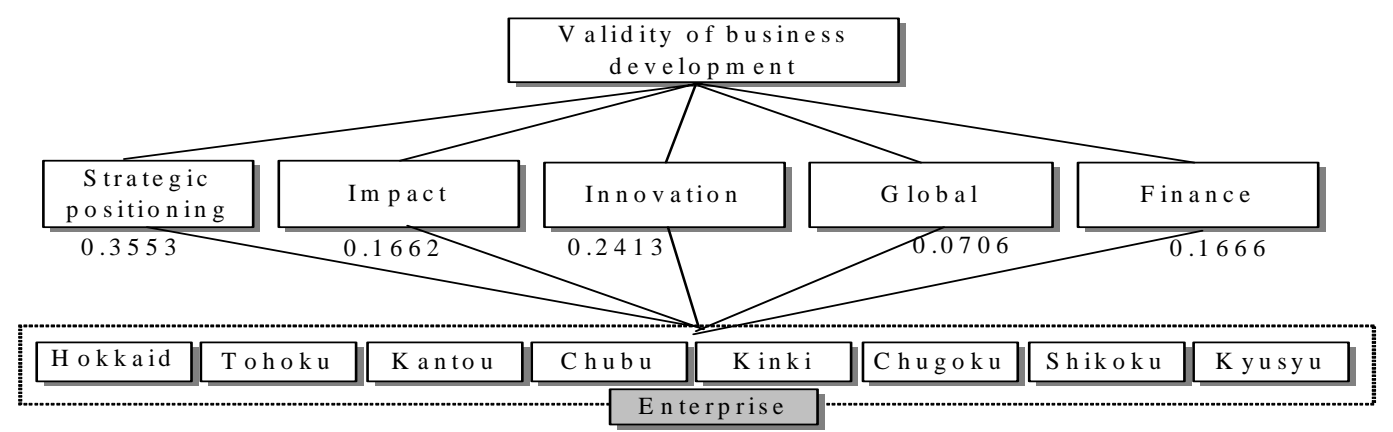

Fig.1 The weight between criteria in business development and hierarchy for evaluation think the venue of the Expo has to be decided by various factors.

The priority level in business activities is based on multipurpose evaluation, strategic positioning (SP), impact to investment, reformation for business development, internationalism as global activity, and a financial side. Fig.1 showed the weight of the business development in company activities by using the Analytic Hierarchy Process (AHP) by making the mainstay layer of the enterprise a testee. Here, as a result, weight reformed of a strategic positioning and the organization appeared high. This result shows that what the other companies couldnot do is intended to want to escape from the balance sheet recession . We think that this result was the one that original what should be in the bussiness activity is shown, and that it was appropriate.

\section{Criteria to Aichi Expo and evaluation data of candidate site}

\subsection{Criteria of strategic positioning}

The science and the technology of the 20th century created a rich material civilization, and activated the exchange of the person and information globally by mass displacement, high-speed

Table 1 Weight between components of strategic positioning

\begin{tabular}{l||c|c|c|c||c}
\hline & Itatica & Energy saving & Mobility & Commmication & Weight \\
\hline \hline Itatica & 1 & 3 & 5 & 5 & 0.5596 \\
\hline Energy saving & $1 / 3$ & 1 & 3 & 3 & 0.2495 \\
\hline Mobility & $1 / 5$ & $1 / 3$ & 1 & 1 & 0.0955 \\
\hline Communication & $1 / 5$ & $1 / 3$ & 1 & 1 & 0.0955 \\
\hline
\end{tabular}
transportation, and the means of communication.

Therefore, it was an issue of the earth society all constituent members to pursue sustainable symbiosis of all "Life" on the earth in the all earth view in the 21st century. And, the meaning of the Aichi Expo is in the declaration of Japan's taking the lead and grappling with the issue of the 21st century.

Now, let's confirm the profitability of the business based on "Wisdom of nature" that is the theme of the Expo. The indexes are assumed to be a ratio of the area of the forest as the environmental agreement level, an energy consumption by uniting about the city and nature, an infrastructure of telecommunication (diffusion of the communication net), and traffic convenience to shorten the distance feeling of the city and nature (number of possession of the car).

Then, the criteria are named Itatica, energy saving, mobility, and communication respectively. Table 1 shows the result of the weight vector between the criteria obtained by the cooperation of the adult 
student who works for the enterprise.

\section{(1)Itatica with nature}

It is necessary to display Itatica with nature by the distance of time from the center of a city. However, because the definition of "Forest" was not easy, it was approximated by area ${ }^{(3)}$ of the forest for each home. Conversion for each home is an operation for convenience because characteristics of the region are made an index, and the result of regularization

Table 2 Evaluation of Itatica with nature

\begin{tabular}{l|c|c|c|c}
\hline Area & $\begin{array}{r}\text { Rate of area of forest } \\
\text { (ha/family) }\end{array}$ & Ratio to average & Correction value & Regularization \\
\hline \hline Hokkaido & 438.5 & 3.5906 & 0.2785 & 0.4711 \\
\hline Tohoku & 214.8 & 1.7591 & 0.5685 & 0.9615 \\
\hline Kanto & 50.9 & 0.4170 & 0.4170 & 0.7054 \\
\hline Chubu & 72.2 & 0.5912 & 0.5912 & 1 \\
\hline Kansai & 24.4 & 0.1999 & 0.1999 & 0.3382 \\
\hline Chugoku & 61.6 & 0.5048 & 0.5048 & 0.8538 \\
\hline Shikoku & 66.1 & 0.5411 & 0.5411 & 0.9152 \\
\hline Kyusyu & 48.4 & 0.3962 & 0.3962 & 0.6702 \\
\hline Average & \multicolumn{2}{|l}{}
\end{tabular}
doesn't change even if it is converted by the population (same operation). The larger the rate of the area of the forest is the higher Itatica with nature, oppositely, the maintenance rate of a necessary infrastructure for business activities becomes small. Therefore, Itatica level was shown according to the ratio to a nationwide mean value which was adjusted to one. However, the maintenance rate of the infrastructure decreases Hokkaido and Tohoku though it grows more than a nationwide mean value, but the maintenance rate of the infrastructure decreases. Therefore, an evaluation value Itatica in this region is displayed by the reciprocal, it was tried to regularize the height as one.

\section{(2) Energy saving}

Business activities demand the large quantity of energy. The energy source is divided into the electric power and the city gas. Here, energy consumption is evaluated by using electric power ${ }^{(4)}$. When power consumption is large, it is assumed that energy consumption is low because the amount of the exhaust of $\mathrm{CO}_{2}$ grows, too. The national average of the energy consumption was assumed to be one as well as the operation with Itatica with nature, and energy saving was shown in the ratio. Moreover, it was displayed by the reciprocal of the evaluation value when one was exceeded.

\section{(3) Mobility}

The easiness of communications of "face to face" is measured by the degree of the maintenance of a large-scale traffic transport network. However, it is thought that the role of the car increases by the road network with a high easiness and maintenance rate of communications with "Forest". Therefore, an easy index for the movement was shown by number of the passenger car possession ${ }^{(5)}$. And, it was tried to regularize the height as one too.

\section{(4) Communication}

Telecommunication is possible as for communications that exceed the time distance and the space. It is because of the idea that the importance will increase in the future. The communication was displayed from the ratio of internet users ${ }^{(6)}$.

\subsection{Evaluation of economical impact}

\section{(1) Basic idea}

An economical impact showed the activity degree of a coordinated level or the organization body in the organization from the standpoint of the enterprise. In this research, an economical impact according to the construction investment was derived by the regional input-output analysis by using the model that 
the trade between regions was considered without taking the concept of rate of self-sufficiency. Then, Chubu enterprise and non-Chubu enterprise are shown 1 and 2 respectively by the suffix, so input coefficient $\boldsymbol{A}$ amount of production $\Delta \boldsymbol{X}$ import coefficient $\boldsymbol{M}$ final demand $\Delta F$, the following equation were obtained.

$$
\begin{aligned}
& \Delta \boldsymbol{X}_{1}=\boldsymbol{A}_{11} \Delta \boldsymbol{X}_{1}+\Delta \boldsymbol{F}_{1}+\boldsymbol{M}_{12} \Delta \boldsymbol{X}_{2}-\boldsymbol{M}_{21} \Delta \boldsymbol{X}_{1} \\
& \Delta \boldsymbol{X}_{2}=\boldsymbol{A}_{22} \Delta \boldsymbol{X}_{2}+\Delta \boldsymbol{F}_{2}+\boldsymbol{M}_{21} \Delta \boldsymbol{X}_{1}-\boldsymbol{M}_{12} \Delta \boldsymbol{X}_{2}
\end{aligned}
$$

The relation between final demand and the amount of the production was represented.

$$
\left(\begin{array}{c}
\Delta \boldsymbol{F}_{1} \\
\Delta \boldsymbol{F}_{2}
\end{array}\right)=\left(\begin{array}{cc}
\boldsymbol{I}-\boldsymbol{A}_{11}+\boldsymbol{M}_{21} & -\boldsymbol{M}_{12} \\
-\boldsymbol{M}_{21} & \boldsymbol{I}-\boldsymbol{A}_{22}+\boldsymbol{M}_{12}
\end{array}\right)\left(\begin{array}{c}
\Delta \boldsymbol{X}_{1} \\
\Delta \boldsymbol{X}_{2}
\end{array}\right)
$$

And following equation were obtained when the retrogression row was used.

$$
\begin{aligned}
\left(\begin{array}{c}
\Delta \boldsymbol{X}_{1} \\
\Delta \boldsymbol{X}_{2}
\end{array}\right) & =\left(\begin{array}{cc}
\boldsymbol{I}-\boldsymbol{A}_{11}+\boldsymbol{M}_{21} & -\boldsymbol{M}_{12} \\
-\boldsymbol{M}_{21} & \boldsymbol{I}-\boldsymbol{A}_{22}+\boldsymbol{M}_{12}
\end{array}\right)^{-1} *\left(\begin{array}{c}
\Delta \boldsymbol{F}_{1} \\
\Delta \boldsymbol{F}_{2}
\end{array}\right) \\
& =\left(\begin{array}{ll}
\boldsymbol{B}_{11} & \boldsymbol{B}_{12} \\
\boldsymbol{B}_{21} & \boldsymbol{B}_{22}
\end{array}\right) *\left(\begin{array}{c}
\Delta \boldsymbol{F}_{1} \\
\Delta \boldsymbol{F}_{2}
\end{array}\right)
\end{aligned}
$$

As a result, the amount of the production of Chubu area enterprise was possible to simplify $\Delta \boldsymbol{X}_{1}=\boldsymbol{B}_{11} \Delta \boldsymbol{F}_{1}$.

\section{(2) Amount of investment}

1/3 of the amount o the EXPO was paid by the Japanese government .And Aichi Prefecture and Nagoya City were paid 1/3 contribution a remaining investment together. However, the investment of Aichi Prefecture was amounts of money other than the contribution, and the amount of investment by the country was 1/3 of 135 billion yen. In addition, the investment of Aichi Prefecture was other than the contribution, so the amount of the investment of the private company was not summed up. As a result of the investigation as follows, we assigned the amount to each industrial section. When ROI(Return of Investment) was made the ratio of the final spread to the investment, the Kanto enterprise grows most. The reason is possibly thought that there are a lot of headquarters, summing up the amount of money of dealings at headquarters, and the propensity to consume are high. Because consumption is high, the reason is thought to be a result in which the income is low by the Hokkaido enterprise and the Kyushu enterprise though ROI is growing. So-called "Savings rate" is high because the propensity to consume is low, and it is shown to reduce ROI in the Chubu enterprise. When ROI(Return of Investment) is made the ratio of the final spread to the investment, the Kanto enterprise grows most. The reason is possibly thought that there are a lot of headquarters, summing up the amount of money of dealings at headquarters, and the propensity to consume are high. Because consumption is high, the reason is thought to be a result in which the income is low by the Hokkaido enterprise and the Kyushu enterprise though ROI is growing. So-called "Savings rate" is high because the propensity to consume is low, and it is shown to reduce ROI in the Chubu enterprise. In "Chubu I/O table" used to calculate, it is thought that it was leveled by the economic effect of other prefectures where an economic effect are low. However, the effect of the repercussion of the trade with the non- Chubu enterprise cannot be disregarded even if it is seen on a nationwide scale. 
Table 3 Economic effect

\begin{tabular}{l|c|c|c|c|c|c||c}
\hline & Consumption & Direct spread & The first spread & The second spread & The final spread & ROI & Normalization \\
\hline Hokkaido & 72.6 & 326,998 & 148,728 & 191,569 & 667,295 & 2.041 & 0.8335 \\
\hline Touhoku & 72.0 & 326,998 & 137,030 & 171,941 & 635,968 & 1.945 & 0.7943 \\
\hline Kanto & 72.9 & 326,998 & 246,497 & 227,134 & 800,629 & 2.448 & 1 \\
\hline Chubu & 69.2 & 326,998 & 199,520 & 171,544 & 698,062 & 2.135 & 0.8719 \\
\hline Kansai & 73.3 & 326,998 & 203,763 & 200,724 & 731,484 & 2.237 & 0.9136 \\
\hline Ctugoku & 71.5 & 326,998 & 219,605 & 159,695 & 706,298 & 2.160 & 0.8822 \\
\hline Shikoku & 73.2 & 326,998 & 148,137 & 168,987 & 644,122 & 1.970 & 0.8045 \\
\hline Kyusyu & 73.2 & 326,998 & 195,983 & 194,202 & 717,183 & 2.193 & 0.8958 \\
\hline
\end{tabular}

\subsection{Innovation}

It was thought that continued source of the enterprise was an organizational culture, and tried the evaluation of a soil innovated of the enterprise. The evaluation of the innovation was tried in total of each establishment region for the Tokyo Stock Exchange first section market manufacture company. However, innovated soil was requested at rates of present number ${ }^{(7)}$ of manufacturing of headquarters addresses because there was no big change in the address even if the address in a present headquarters was requested.

\subsection{Internationalism}

Number ${ }^{(8)}$ of international airports of getting on and off guests was used as an evaluation of internationalism.

Kansai International Airport is thought for an international sightseeing spot such as this is Kyoto and Nara though there are a lot of numbers of getting on and off guests to exist.

Advancing the internationalization in Chubu region where the person's movement is attended if Chubu International Airport opens a port sees for the long term and it is important.

\subsection{Soundness of finance}

There were a grant from the country and a privilege such as the prolongment at the repayment period for the municipality, and " Soundness of finance " was displayed by "Financial capability index ${ }^{(9) " ~ t o ~}$ divide standard financial revenues for the local government in a certain fiscal year in the base fiscal demand. If this index falls below one, it is a delivery group of the tax money allocated to local governments, and if one is exceeded, it becomes no delivery group. The Finance of Chubu part company body is rich and is just next to Kanto company body . It is accompanied with flip of high save-rate .

\section{Candidate site selection and economic policy of Aichi Expo}

\subsection{Evaluation of candidate site}

The candidate site eligibility of the Aichi enterprise was evaluated overall by using AHP and addition method based on these data. That was, the weight vector of the evaluation item is multiplied by the evaluation value of the enterprise, and the total was requested. By the way, the independence between the evaluation value was a basic principle of AHP.

In Table 4, the evaluation value of a strategic positioning of Chubu enterprise showed that it was higher than another enterprise. Therefore, it was able to conclude that Chubu enterprise was a suitable enterprise for the theme of this Expo. Moreover, it was expected that there will be little difference between the part enterprise and Kanto enterprise while making it show in Table 4 in the comprehensive evaluation. A strategic positioning was high, and Chubu enterprise was flexible, and obtained priority 
high from a strategic standpoint by introducing the aspect of the evaluation that considered the corporate strategy like this the resource that developed the business and the organization body.

Table 4 Comprehensive evaluation of candidate site

\begin{tabular}{l|c|c|c|c|c|c||c}
\hline \multirow{2}{*}{ weight } & SP & Imapct & Inovation & Global & Finace & & $\begin{array}{c}\text { Comprehensive } \\
\text { evaluation }\end{array}$ \\
\cline { 2 - 8 } & 0.3553 & 0.1662 & 0.2413 & 0.0706 & 0.1666 & & 0.0755 \\
\hline \hline Hokkaido & 0.3768 & 0.8335 & 0.0651 & 0.1316 & 0.4903 & 0.3791 & 0.1064 \\
\hline Tohoku & 0.8432 & 0.7943 & 0.0571 & 0.1192 & 0.4835 & 0.5343 & 0.1719 \\
\hline Kanto & 0.6229 & 1 & 1 & 0.9617 & 1 & 0.8633 & 0.1717 \\
\hline Chubu & 1 & 0.8719 & 0.6845 & 0.6028 & 0.9251 & 0.8620 & 0.1502 \\
\hline Kansai & 0.5075 & 0.9136 & 0.8867 & 1 & 0.8242 & 0.7540 & 0.1138 \\
\hline Chugoku & 0.7602 & 0.8822 & 0.2333 & 0.1092 & 0.5452 & 0.5716 & 0.1004 \\
\hline Kyikoku & 0.7160 & 0.8045 & 0.1784 & 0.0396 & 0.4222 & 0.5043 & 0.1101 \\
\hline
\end{tabular}

\subsection{Examination of general evaluation technique}

When the comprehensive evaluation is displayed by the matrix, it becomes the following.

$\left(\begin{array}{ccccc}0.376769 & 0.833462 & 0.065124 & 0.131616 & 0.490262 \\ 0.843183 & 0.794335 & 0.057074 & 0.119224 & 0.483529 \\ 0.622930 & 1 & 1 & 0.961736 & 1 \\ 1 & 0.871891 & 0.684492 & 0.602813 & 0.925058 \\ 0.507460 & 0.913637 & 0.886715 & 1 & 0.824195 \\ 0.760206 & 0.882179 & 0.233311 & 0.109186 & 0.545194 \\ 0.715951 & 0.804520 & 0.178423 & 0.039595 & 0.422187 \\ 0.744160 & 0.895774 & 0.130242 & 0.344682 & 0.503274\end{array}\right) *\left(\begin{array}{l}0.355251 \\ 0.166233 \\ 0.241339 \\ 0.070581 \\ 0.166595\end{array}\right)=\left(\begin{array}{l}0.3791 \\ 0.5343 \\ 0.8633 \\ 0.8620 \\ 0.7540 \\ 0.5716 \\ 0.5043 \\ 0.5529\end{array}\right)$

In this case, it is an evaluation of one direction in the appearance though Additional method is not seen. When there is an evaluation from the candidate site, it is thought that the evaluation items will be compared from alternatives in Fig.1 and the application of Analytic Network Process (ANP) is possible.

In this case, Super-matrix of Saaty ${ }^{(10)} \boldsymbol{S}$ is non-negative-matrix.

And, because the row harmony of the super-matrix is adjusted to one, it is known to settle a constant value at accumulation. However, when the row harmony is not one like this research, it is changed to $S_{1}$ matrix in the next page. The small matrix on the left is an evaluation procession concerning the business development with the mainstay layer of the corporate.

The matrix on upper right is an evaluation procession who saw from each enterprise, if it is equal to the evaluation of the mainstay layer of the enterprise, the eigenvector can be requested from the theorem of Perron-Frobebenius. However, when the row harmony of the super-matrix do not

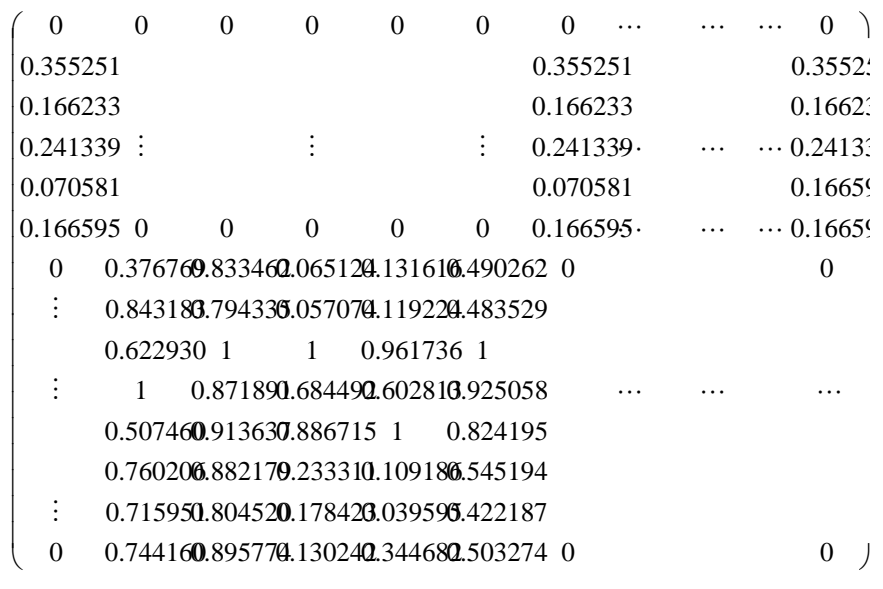
adjust to one, it is to happen the problem to vibrate the maximum eigenvalue when all of the diagonal matrix are adjusted to 0 .

It cannot be assumed to be an answer to eigenvector to the maximum eigenvalue of super-matrix. 
Then, we requested for the values other than 0 to put in all of the diagonal matrix and the eigenvector by single precision by the Power method The value of the weight vector by the eigenvector is an integrated evaluation value of Table 4 . When the diagonal matrix is all 0 , the maximum eigenvalue vibrates, if the frequency is repeatedly assumed to be 200 times, a steady answer is not obtained for eigenvalue vibrates.

In addition, the convergence condition is made severe, and the value of the diagonal matrix is changed, it is settled to a maximum value of 50 , but when the diagonal matrix is adjusted to all one, the eigenvector is settled with stability, and fast. Moreover, the eigenvector changes when the diagonal matrix is enlarged and some decimals change in about the third place, however when the diagonal matrix is adjusted to all one, the eigenvector is obtained that the diagonal matrix is the same as the time of all 0 . Therefore, it is thought that it is preferable to adjust the diagonal matrix to all one when alternatives are absolutely evaluated and to request the eigenvector.

As this reason, though this Power method doesn't consider the complex number, when the value of the diagonal matrix is 0 , there are two or more partial spaces of the eigenvalue as which the size is almost the same, it is thought that settling worsens. However, when the value of the diagonal matrix is wrong 0 , it only makes the difference that is in the size of a partial space of the eigenvalue because of the size of the diagonal matrix, the eigenvector to the maximum eigenvalue is only done by the constant twice, regularized weight-vector becomes one as well as the eigenvector. However, this processing is the operation of a small figure and a large figure, so the rounding error margin grows, the rounding error margin grows and the difference of weight-vector is generated, it seems that condition of the small rounding error margin is one at the weight vector .By the way, alternatives requested by absolute grading method, it becomes the same answer that the weight vector when the row harmony of value is adjusted to one and weight vector by a couple of comparison procession of AHP that uses the evaluation value by absolute grading $w_{i} / w_{j}$.Therefore, it is convenience to adjust the row harmony to one that the evaluation that convenience of unnecessarily calculating the weight vector by the eigenvector, it is convenience that calculation to the weight vector by the eigenvector is unnecessarily to adjust the row harmony to one, and adjusts the row harmony to one is seemingly appropriate. However, this procession $\boldsymbol{S}_{1}$ though it did not cause, $\boldsymbol{S}_{1}$ element $(9,2),(10,4)$ changing it into 0.6 and 0.8 ,so weight vector by the absolute grading method becomes $\boldsymbol{W a}=(0.0752,0.1060,0.1696,0.1765,0.1496,0.1134,0.1000)$, however weight vector of that he row harmony is a one becomes $\boldsymbol{W n}=(0.0672,0.0950,0.1868,0.1849,0.1658,0.1063,0.0922,0.1018)$, The order of the Kanto enterprise and Chubu enterprise was reversed.

If the evaluation value by the absolute grading method is all one, the row harmony is adjusted to one, the weight vector evenly becomes $1 / 8$, though it is a high absolute grading value, the weight vector lowers, the meaning of the absolute grading method that assumes the goodness to be one is lost.

It is thought that the evaluation of alternatives shows that additional law of the effect is not approved, thinking the effect to point out to Tamura $^{(11)}$ from standpoint of utility theory

\subsection{Relation between Aichi Expo and economic policy \\ (1) Resolution to investment}


It becomes 70 billion yen near when the amount of money that can be collected as a so-called tax is presumed from an economical impact, and this corresponds about the amount of the investment $30 \%$ near. As for becoming this amount of money, it is necessary to evaluate the municipality that invests, and the operating profit by next year's opening is considered, so it is expected that it is possible to collect it almost, it is thought that the opinion with "It is necessary to give priority to other measures besides the investment in the Expo" is not hit. Even though the scale was reduced, it is thought that it is the one that an original responsibility as the administration that stares at the view to the future was accomplished, and a resolution.

\section{(2) Check of model and economic policy}

The difference with this model is 1 billion 784 million yen by $\Delta \boldsymbol{X}=(\boldsymbol{I}-\boldsymbol{A})^{-1} \Delta \boldsymbol{F}$ that the effect model in my entire country is simplified, it doesn't have the error margin by almost two models, and the validity of this model be confirmed.

By the way, ROI in Chubu area is 3.211 and though the amount of money is few, the effect is growing. From this Economical effect is " $\boldsymbol{G D P}=\boldsymbol{I}+\boldsymbol{C}$ I", it is understood that the influence that the vicinity and the Aichi Expo exert on economy is large .It is because that the influence for Clause 2 in " $\Delta \boldsymbol{X}_{1}=\boldsymbol{B}_{11} * \Delta \boldsymbol{F}_{1}+\boldsymbol{B}_{12} * \Delta \boldsymbol{F}_{2}$ " is large. That is, it is normal economy that the investment and consumption push up the GDP.However, the corporate is all-out in the restoration of the bad loan according to a low interest rate. On the other hand, it is not expected that GDP rises greatly that consumption also gets cold by the restructuring etc. to improve one's physical condition.

Table 5 Check and effect of model

\begin{tabular}{|c|c|c|c|c|c|c|}
\hline & & $\begin{array}{l}\text { Amount of } \\
\text { investment of } \\
\text { project }\end{array}$ & Chubu area & $\begin{array}{c}\text { Un Chubu } \\
\text { area }\end{array}$ & $\begin{array}{l}\text { The whole } \\
\text { country }\end{array}$ & \\
\hline 1 & 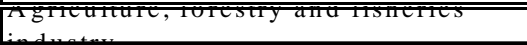 & 3,767 & 377 & 3,390 & 3,767 & \\
\hline 2 & Mining & 14,021 & 1,402 & 12,619 & 14,021 & \\
\hline 3 & Food and cigarette & 0 & 0 & 0 & 0 & \\
\hline 4 & M aterial & 94,655 & 9,465 & 85,189 & 94,655 & \\
\hline 5 & Machine & 49,808 & 4,981 & 44,828 & 49,808 & \\
\hline 6 & O ther manufacturing & 89,134 & 8,913 & 80,221 & 89,134 & \\
\hline 7 & Construction and construction repairs & 519 & 52 & 467 & 519 & \\
\hline 8 & Public works & 0 & 0 & 0 & 0 & \\
\hline 9 & Other engineering works construction & 0 & 0 & 0 & 0 & \\
\hline 10 & Public utilities & 1,500 & 150 & 1,350 & 1,500 & \\
\hline 11 & Commerce and transportation & 44,318 & 4,432 & 39,886 & 44,318 & \\
\hline \multirow[t]{3}{*}{12} & Fimance, misuramce, iedrestate, antu & 29,276 & 2,928 & 26,349 & 29,276 & \\
\hline & Total & 326,998 & 32,700 & 294,298 & 326,998 & \\
\hline & & Effect & 72,294 & 962,494 & $1,065,704$ & $-30,916$ \\
\hline
\end{tabular}

The country works out the reduction in the annual expenditure, the economy of our country keeps the state of balance under the balance recession not preferable, and the effect by the Aichi Expo has been limited.

Kinoshita ${ }^{(12)}$ and Richardocu ${ }^{(13)}$ advocate the economic policy under the balance sheet recession. The maximization problem of the profit in the corporate activity and the minimization problem of 
uselessness are the dual problems, and the same profit will be obtained as a result. The precondition in this case is, it is assumed that the corporate has some degree of freedom in though there is a restriction. Therefore, the economic policy of a present improving one's physical condition also has validity when thinking about company activities from the dual problem in a strict meaning. However, though the low interest policy turns to the compression of the bad loan the capital, and takes an action similar as for the bank, in the situation in which the repayment capital is stocked, as for the economic policy of the improving one's physical condition, the effect can be expected only of the compression of the bad loan.

Moreover, the setting of the government bond frame has resulted give impetus the brake of company activities and the consumption activity.

That is, the precondition of the dual problem has not been approved. On the other hand, the recovering corporate power is consumed again, it is not raised the interest rate, and the economic policy is a situation that cannot help being left to the mechanism of the market.

In this research, our country located it by the Aichi Expo is that our country takes the lead and pursues sustainable symbiosis with all "Life" on the earth, but the economic policy to make the lively activity of business corporations awake might be inevitable. Therefore, it can be said that the compression of the bad loan is a natural act as company activities, and that the responsibility that brings fallacy of composition is in the mistake of the economic policy. However, more seriously, there is a reason why such fallacy of composition appears because the economic policy in the country is not trusted by the enterprise, it is thought the corporate is to make use of the economic policy.

It is a conversion of the economic policy to escape from "Liquidity trap" that Keinz pointed out. If the investment scale reduces, and the Aichi Expo to which local will bear the majority, an economic spread only in Chubu area corporate becomes 2.135 by ROI, it becomes 3.211 and it becomes 3.25 in my entire country. It is thought that the chance for the impact to economy to become small in a local investment if this place in which it means it is not invested in the whole, and to escape from the balance sheet recession was lost.

In the Aichi Expo, A lot of people, things, and money from the world are invested in our country, it is thought that it will not be possible to get rid of the liquidity trap if positive finance is not mobilized to not only Chubu corporate but also Kanto and Kansai, etc.

\section{Conclusion}

(1) In the policy of the country and the local government, the concept of strategy is lacked, however the aspect of company activities in "Strategy" and "Decision making" is introduced, it is the best, and political consideration one in Chubu area as the venue of "Aichi Expo" to have to make a clear distinction.

(2) Though ANP was used to generalize this evaluation technique, the evaluation value of the absolute grading method should not one that the eigenvector regularize, in addition, when you adjust the diagonal matrix to all one, the eigenvector to the maximum eigenvalue can be stably obtained.

(3) In the austerity, it is necessary to send salaam to the resolution of the local municipality that bears the majority of the construction investment, the conversion to the economic policy to which a 
positive investment is attended is indispensable to the escape from a present balance sheet recession to materialize the meaning of the Aichi Expo.

Finally, we wish to express our gratitude to the adult graduate student and the faculty student who helped the Expo society, the Aichi Prefectural government, and the local municipality that cooperates in the research the person in charge and to work.

\section{Reference}

(1) Porter. M.E. 'Theory of competition strategy ( I )' (Takeuchi Hiroshi translation), diamond company, (1999)

(2) Takao Kaneko 'Measurement analysis of regional economy' Sousou syobou 1977

(3) http://www.rinya.maff.go.jp/toukei/genkyou/3kubun.htm

(4) The Ministry of Economy, Trade and Industry material

(5) Control Division material of all the Ministry of Land, Infrastructure and Transport transportation bureau car technological ideas

(6) NetRatings material (2001)

(7) 'Version of the company four seasons of report unlisted' toyokeizaisinposya (2004)

(8) Statistics of the Ministry of Justice entering a country material(2002)

(9) 'Financial capability index' The Management and Coordination Agency (1997)

(10) Saaty,T.L., The Analytic Network Process,RWS Publication(1996)

(11) Tameytuk Tamura other ,"Proposal of described model of hierarchical decision making method (AHP) and adjusted interpretation of Eras order reversal", Journal of the Operations Research of Japan (1998)

(12) Eizo Kinoshita 'Two laws that rule economy' Denkisyoin(2004)

(13) Richard $\mathrm{Cu}$ 'Economics of deflation and balance sheet recession' (Kouicti Sakurai translation), Tokumasyoten (2003) 